\title{
AN ANAESTHETIC RECORD
}

\section{Douglas A. C. MacDonald, M.D., C.M. ${ }^{*}$}

ANAESTHETIC RECORDS are many things to different people. To the senior medical student and possibly to the interne they are examples of symbolization: for the clinical instructor and teacher they supply the essential threads of each anaesthetic story, and provide object lessons of pharmacological and physiological events occurring daily in practice; in clinical research they supply answers to questions of probability and possibility; and to our colleagues in other special fields they may be as incomprehensible as our universe. It is only in recent times that precise and accurate records have been considerèd necessary in anaesthesia, but now they may" well point the way toward future anaesthetic horizons.

We may ask, what information should be on the anaesthetic record? What is significant and what is not? The anaesthetic record should show one of the most detailed events in the patient's clinical life. The story should be complete from the first preoperative visit to the last postanaesthetic visit.

To ensure the accuracy and detail required of such a record and to record by hand the minute to minute events, vital signs, and drugs given, it is necessary to resort to the use of abbreviations and symbols. The form of record presented here was evolved for daily use in a small hospital, and is planned to include the most accurate and detailed information with the least possible writing. It contains less detail than the I.B.M. or Keysort anaesthetic records,' but still retains sufficient flexibility and detail to permit utilization in any hospital practice.

Consideration of this record may be conveniently divided into two sections: the first recording events from the preoperative visit to the termination of anaesthesia, and the second those from the arrival in the recovery room until the final post-anaesthetic visit. The first of these two parts is illustrated in Figure 1.

Each of the two major sections of the anaesthetic record may be considered as consisting of a number of parts, each useful for the recording of specific data. In Figure 2 , the section placed at the head of the chart contains information of a general nature, including the blood group, pre and postoperative diagnosis, operation proposed and operation performed, and the names of the surgeons involved. Much of this information is entered while the chart is being initially assembled.

Figure 3 records the pre-anaesthetic evaluation, and has appropriate areas for recording information gleaned from the chart, and recent laboratory data of interest to the anaesthetist. Features included are the personal anaesthetic history of the patient, what maintenance medication the patient is taking (for example, cortisone), significant recent weight loss (often an indication of subliminal hypovolaemia), and whether the patient has or is suspected of having a full stomach. When the patient has been visited, the operative risk is judged and

"Charlottetown General Hospital, Charlottetown, P.E.I. 


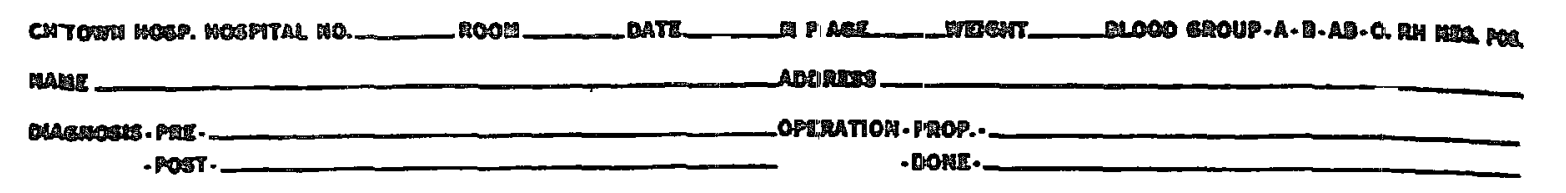

SUECEOA:

IET ASST. ANESTHESIOLOGIST - DOUGLAS HAEDOAML

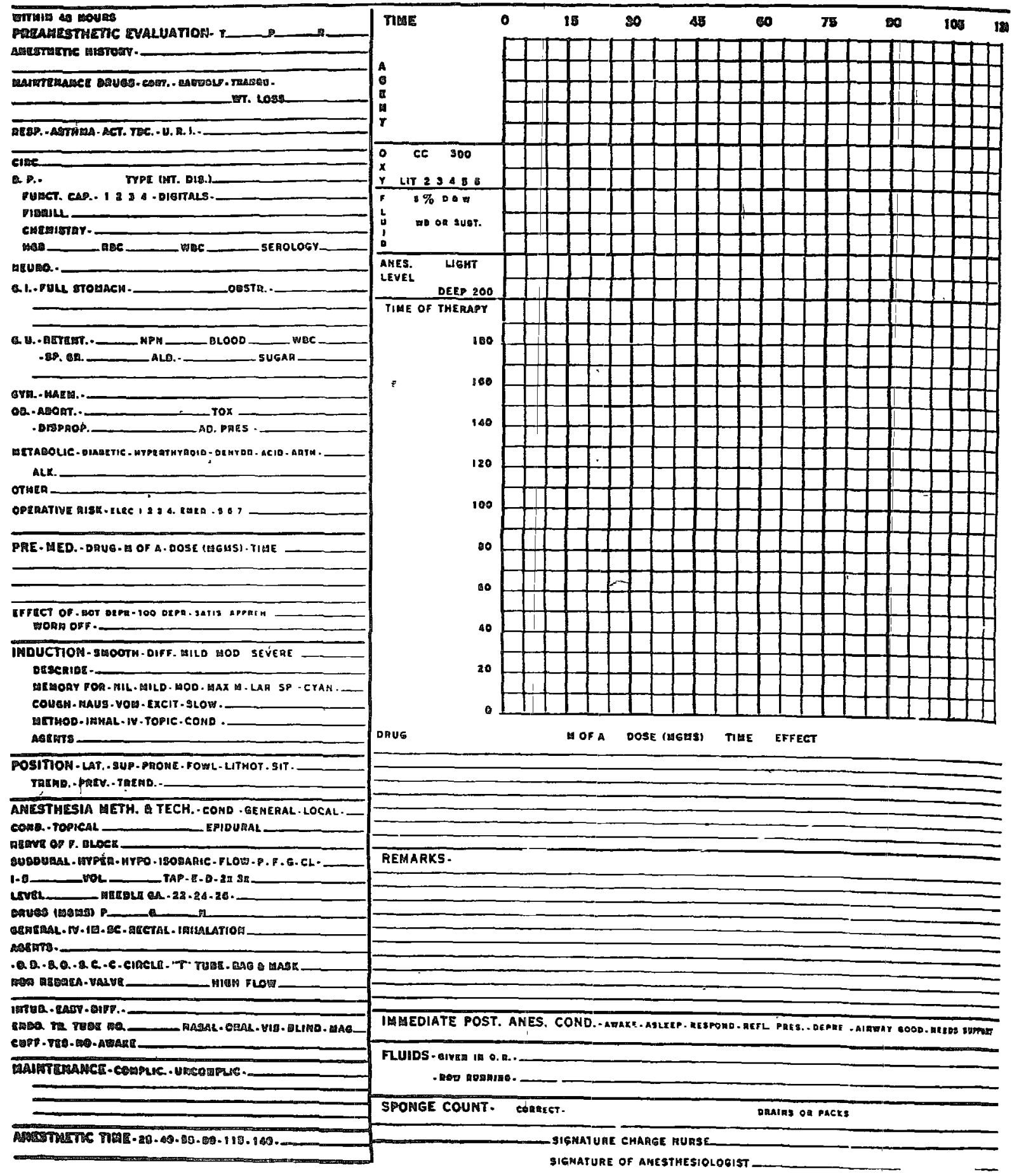


D. A. C. MACDONALD: AN ANAESTHETIC RECORD

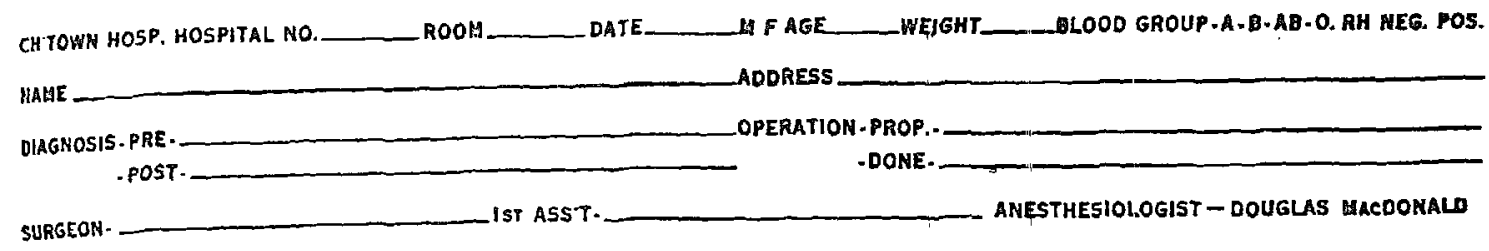

FIGURE 2

WITHIN $\triangle B$ MOURS

PREANESTHETIC EVALUATION-T_______-

ANESTHETIC HISTORY.

MAINTENANCE DRUGS - CORT, - RAUWOLF - TRANQU -

WT. LOSS

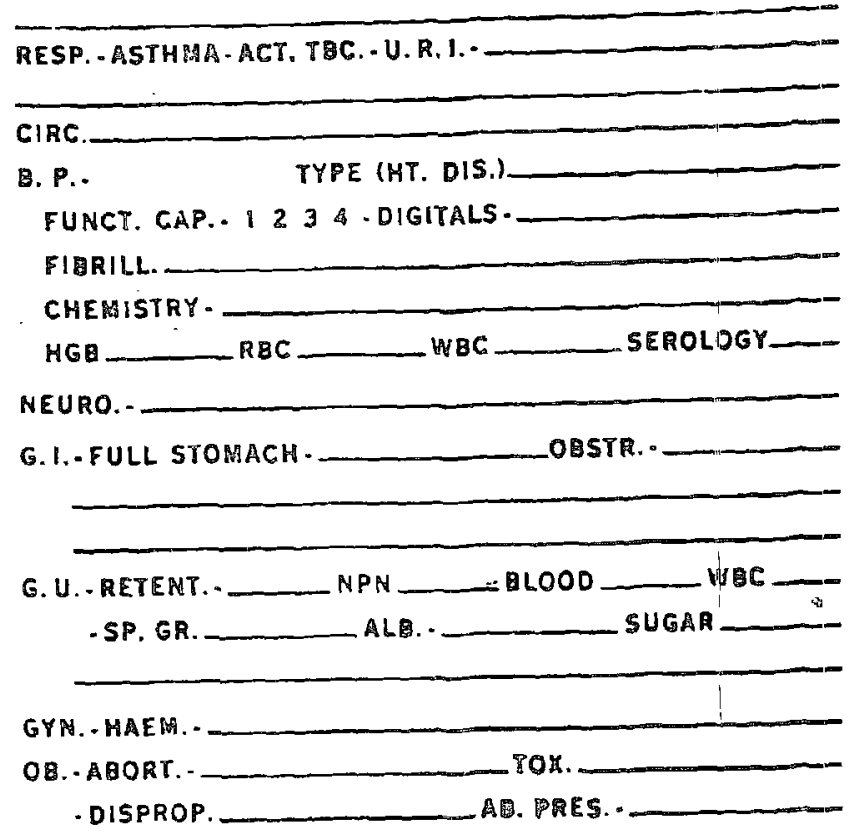

METABOLIC - OIABETIC. HYPERTHYROLO- OEHYOR - ACIO. QRPA.-

ALK.

OTHER

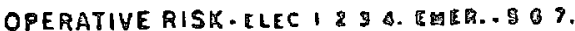

PRE. MED. DRUG - OF A.DOSE (MGRS) - TIRE.

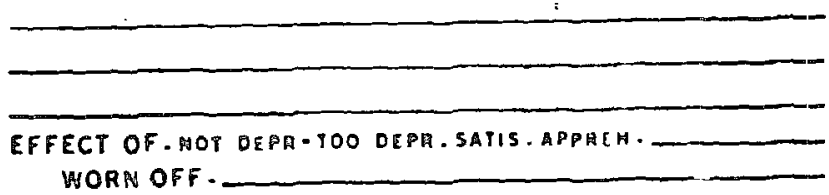

FiguRE 3

recorded, and premedication is ordered. It should be noted that here, and whereever practical in this record, the name of the drug, dose in $\mathrm{mg}$., and method and time of administration are recorded. The effect of premedication will be judged and recorded in the pre-anaesthetic interval. 


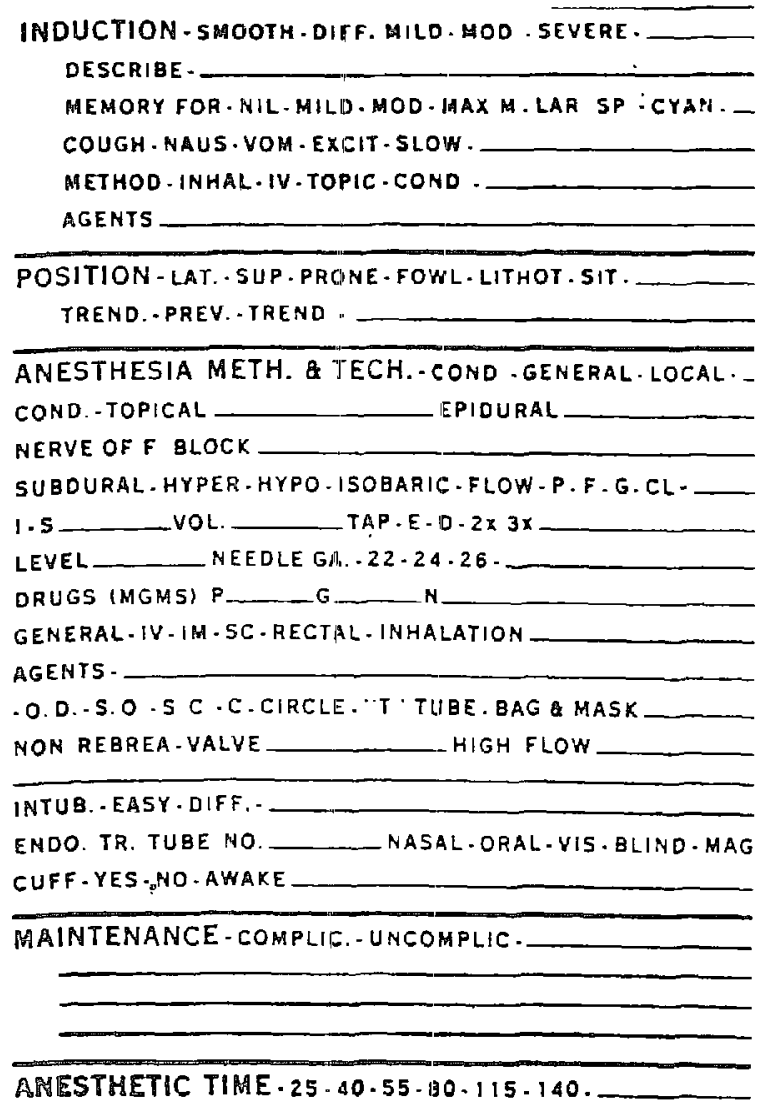

FIGLRE 4

The actual anaesthetic experience is detailed in the section shown in Figure 4. The induction and its progression, the patient's memory for the experience in retrospect, and the method and agents used are described in detail. The position of the patient during induction and maintenance is recorded, and finally the anaesthetic method and technique are detailed. This particular part of the record is difficult to assemble and reduce to a reasonable size, and information in it was limited to local anaesthetic usage. There are three main divisions, with details supplied for conductive and general techniques. When the method is conductive anaesthesia, the appropriate type is encircled. If it is subdural, the baricity, type of flow, interspace, gauge of needle used, ease or difficulty of tap and number of insertions of the needle, and amount and volume of anaesthetic drug, glucose, and vasopressor are all described in detail.

If the method is general, then the mode of adminištration, agents used, and technique are detailed. Maintenance is described in general terms, specific complications are listed, and the anaesthetic time is expressed in economic terms. Anaesthetic agent, rate of oxygen flow, volume and type of fluid used, anaesthetic level, time of drug therapy, and vital signs are signified in the usual way in relation to time on the graph shown in Figure 5.

Figure 6 is a neat and accurate mean\$ of describing specific drug therapy during anaesthesia, and is related to the vital signs through the time of drug therapy in Figure 5. If necessary, this is continued into the section for "remarks." In this section of the chart, the immediate post-anaesthetic condition is recorded 


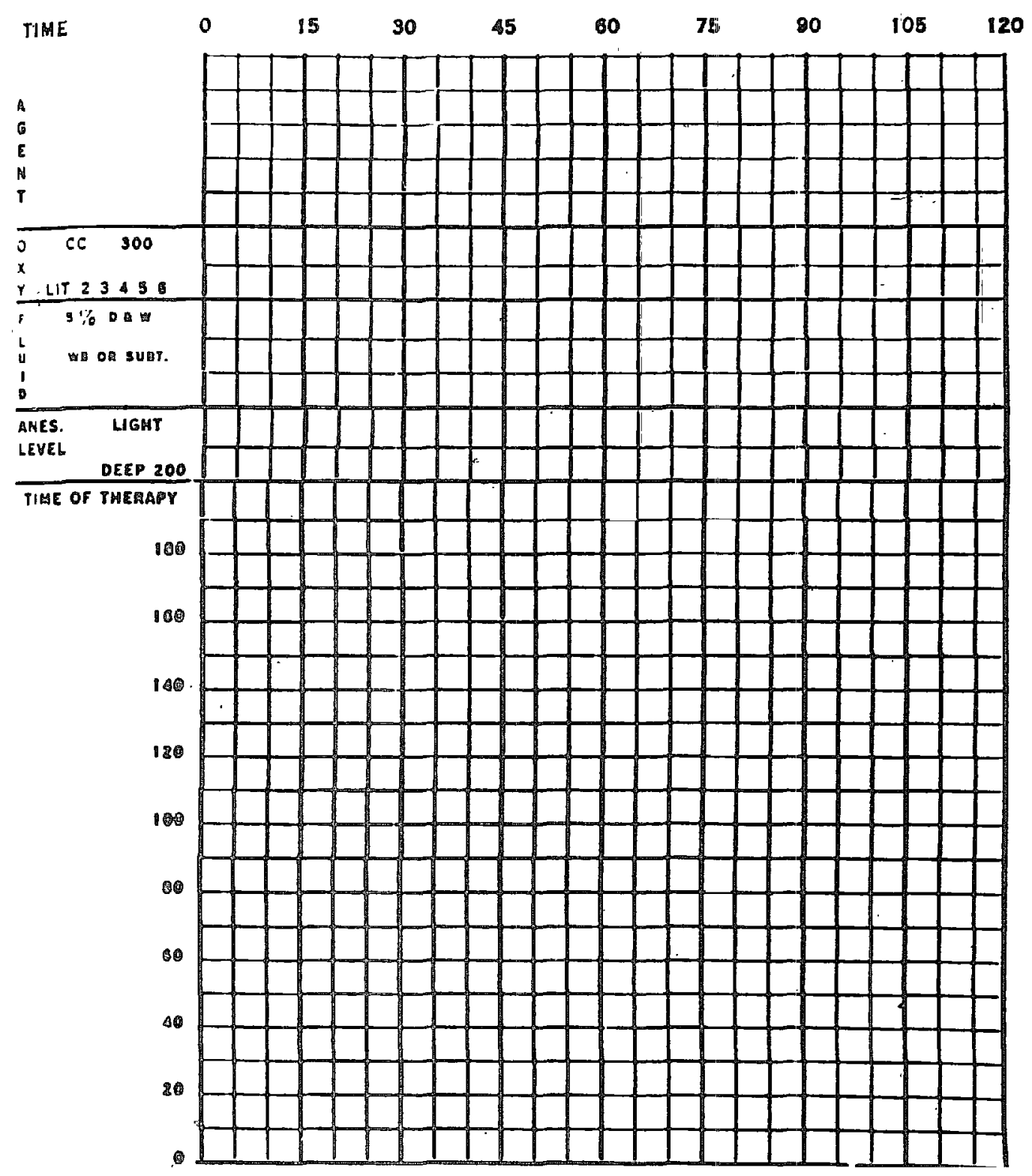

Figure 5

and fluids are accurately described in terms of the amount actually given in the operating room and the amount still running when the patient is discharged to the recovery room. Sponge count and the presence of drains or packs are also entered here, and the record is signed by the charge nurse and the anaesthetist.

The second part of the anaesthetic record deals with that period from arrival in the recovery room to the final post-anaesthetic visit. The events of this period are recorded in the form illustrated in Figure 7.

The vital sign chart which is typical for operating room use is available to the recovery room. Space is demarcated for the description of the airway, recording of the temperature, and the presence or absence of pain, restlessness, hypotension, nausea, or vomiting. The state of consciousness and time of awakening after arrival in the recovery room are also recorded. 


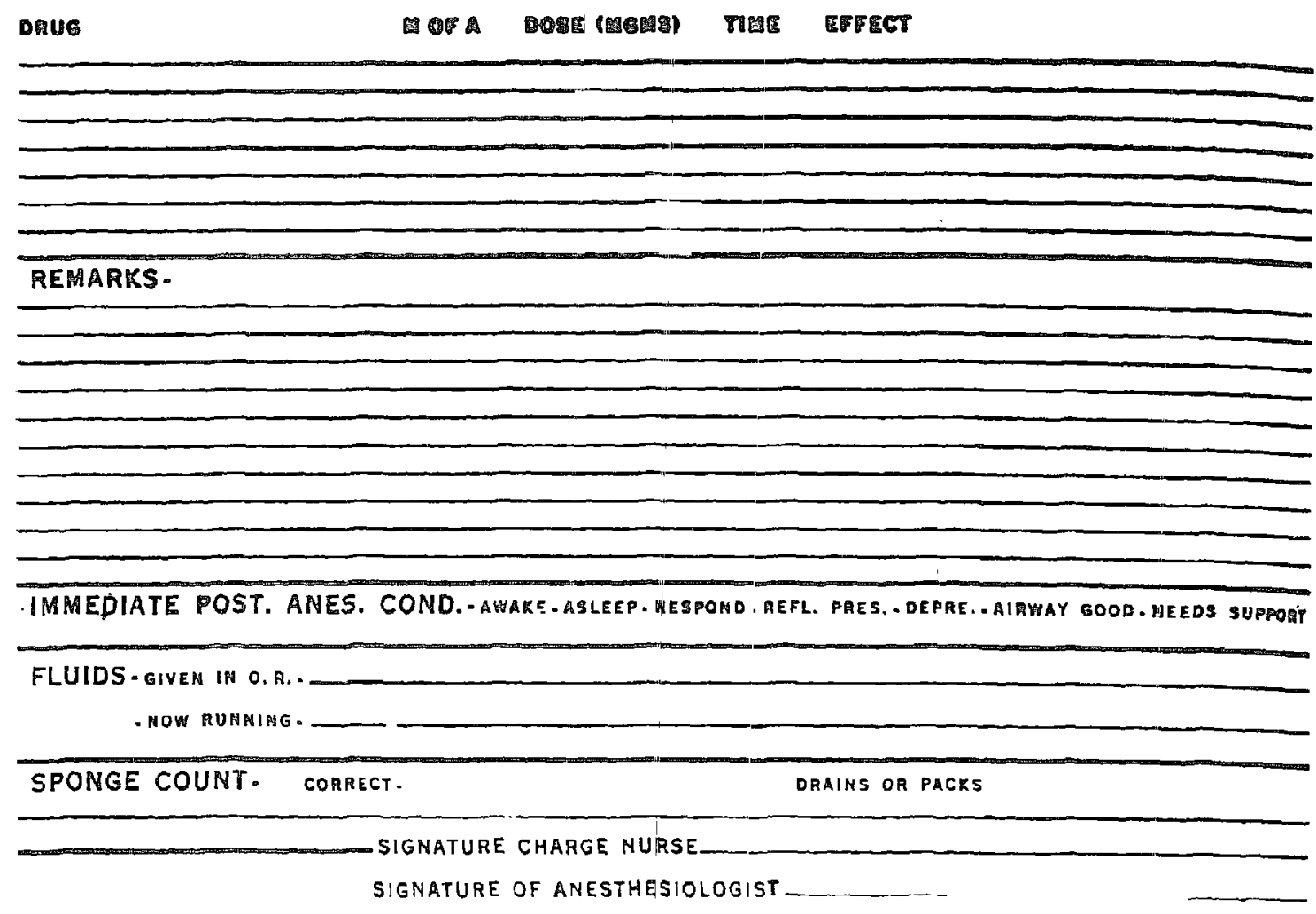

FIGURE 6

The record also includes the description of drugs used with the usual pertinent data, and the total fluid intake and output from the time the patient left the surgical floor until his return. The time of arrival and discharge from the recovery room are entered, and space is provicled for any remarks which the recovery room nurse may wish to make for the benefit of her associates on the surgical floor:

The post-anaesthetic course should also be recorded ini detail, and this is accomplished by simple checking of the conplication in relation to the proper postoperative day column. An adequate area is provided for recording remarks for greater detail.

In order to relate the morbidity recorded during anaesthesia and the postanaesthetic course to the various methods and techniques, agents and regions, it is necessary to have this information in another area. In our hospital we find this most easily done in the regular operating room record book in a special anaesthetic section. Also corded is the date, case number, name, age, operation, surgeon, assistant, preoperative and postoperative diagnosis, hospital number, address, responsible party, and information concerning the patient's insurance coverage such as group number.

Figure 8 illustrates the special section in which we record specific anaesthetic information under proper headings. The main subdivisions such as technique, agent, region, risk, complications, and for a pathology specimen are self-explanatory. Most of the subheadings are simply completed by a check mark and these are totalled at the bottom of the page, and carried forward monthly and yearly. 


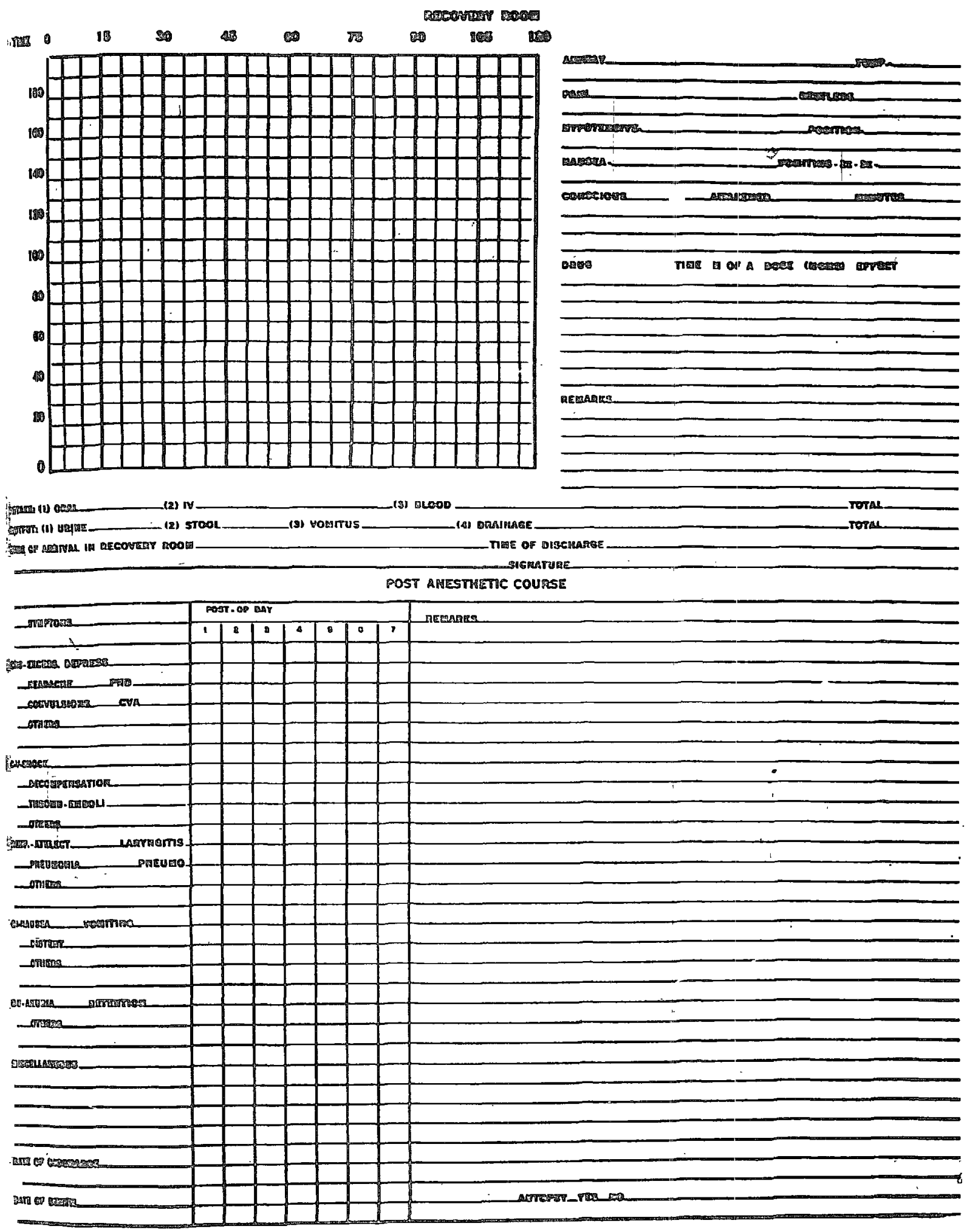




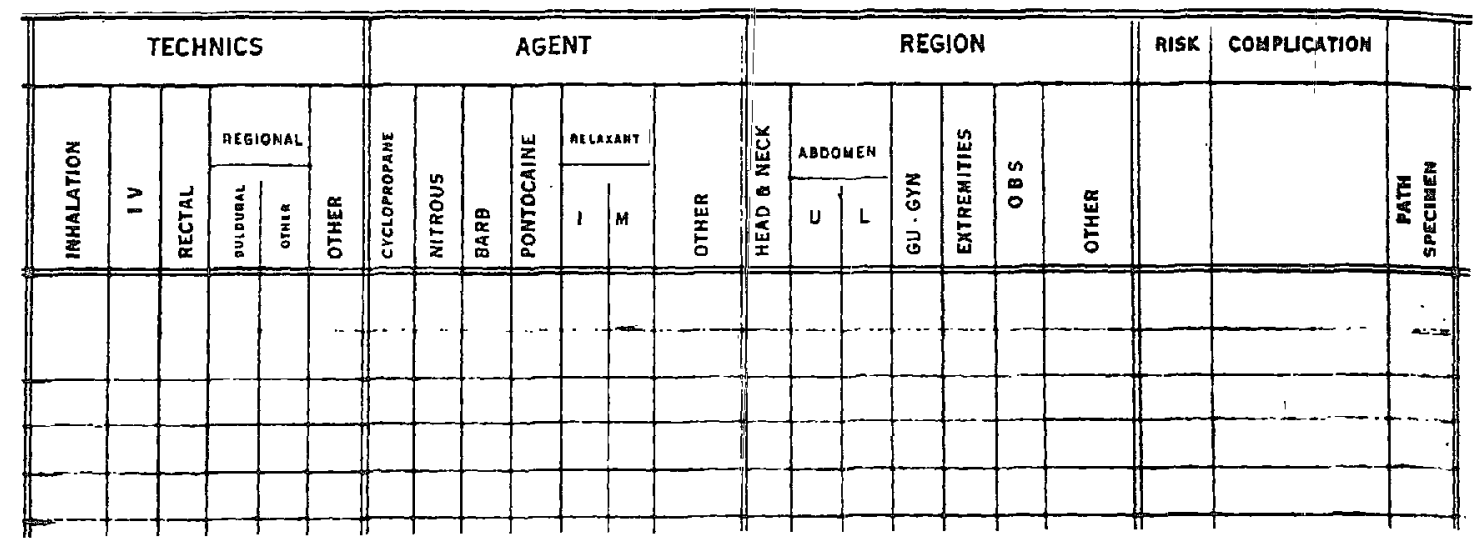

FIGURE 8

However, because of the multiplicity of possibilities under agent and technique, it is again necessary to resort to some form of symbolization or abbreviation. These, of course, will vary with the particular type of anaesthetic practice. Accordingly, under technique in the inhalation column, the particular type is available and marked from the anaesthetic record, such as O.D. (open drop); if an endotracheal tube has been used a " $T$ " is also inserted in this column. Under the section dealing with the agent, symbolization is increased, as rarely used agents such as ether, trilene, and vinethene are listed under "other." Despite the wide use of fluothane it is also listed here.

The relaxant column is a problem, because very of ten succinylcholine alone may be used only for induction, or, on the other hand, another relaxant may be used for maintenance. Therefore, the particular relaxants are indicated according to whether or not they were used for (I) induction and/or (M) maintenance. Operations performed under local anaesthesia are indicated under the column for other agents.

Another problem is to record accurately whether or not an agent is used as a supplement or as the main agent. This has been resolved by varying the size of of the check mark; a small check mark indicating a supplement and a large mark a main agent. In this manner the frequency and type of use of each agent and technique is recorded. Monthly and yearly statistics are available with little effort for study and for comparison with the morbidity statistics. It is expected that following this approach an anaesthetist may alter and confine his techniques and methods to those with the least morbidity.

\section{SUMMAR'}

The author has described a method of keeping accurate and detailed records covering the whole anaesthetic experience from the preoperative visit to the final post-anaesthetic visit. From these records it is possible to study the details of morbidity related to anaesthesia, and it is felt that by following this or a similar outline each anaesthetist will be enabled gradually to decrease his morbidity figures. 
RÉSUMÉ

L'auteur décrit une méthode de conserver, de façon précise et détaillée, tous les faits survenant au cours de l'anesthésie depuis la visite préopératoire jusqu'à la dernière visite postopératoire. Avec de semblables dossiers, l'auteur nous assure qu'il est possible d'étudier tous les détails de la morbidité pouvañt se relier à l'anesthésie et il a la conviction qu'en adoptant cette méthode ou une semblable, les anesthésistes seraient capables de diminuer progressivement leurs| pourcentages de morbidité. 